NASA TECHNICAL

MENORAYDUM

NASA TM X- 52466

$1 \frac{8}{\text { J }}$

GPO PRICE

CFSTI PRICE(S)

Hard copy $(\mathrm{HC})$

Microfiche (MF)

$\$$

$\$$

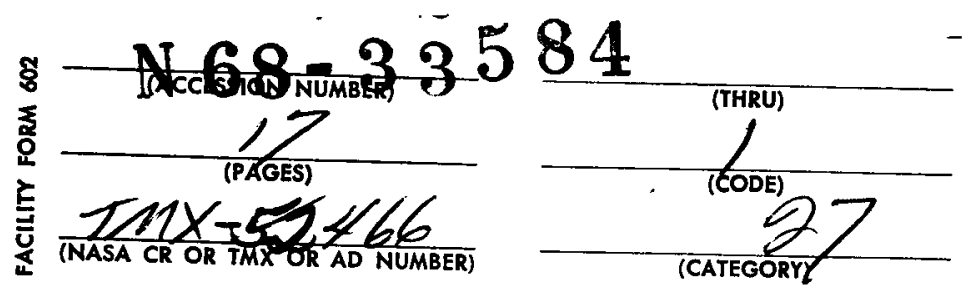

ff 653 July 65

\title{
A REVIEW OF THE POTENTIAL OF LIQUID-METHANE FUEL FOR SUPERSONIC TRANSPORTS
}

by Richard J. Weber

Lewis Research Center

Cleveland, Ohio

TECHNICAL PAPER proposed for presentation at Cryogenic Engineering Conference Cleveland, Ohio, August 19-21, 1968

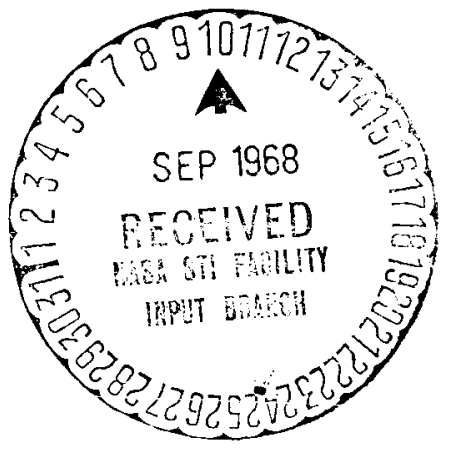


A REVIEW OF THE POTENTIAL OF LIQUID-METHANE FUEL FOR SUPERSONIC TRANSPORTS

by Richard J. Weber

Lewis Research Center

Cleveland, Ohio

TECHNICAL PAPER proposed for presentation at

Cryogenic Engineering Conference

Cleveland, Ohio, August 19-21, 1968

NATIONAL AERONAUTICS AND SPACE ADMINISTRATION 


\title{
A REVIEW OF THE POTENTIAL OF LIQUID-METHANE
}

\author{
FUEL FOR SUPERSONIC TRANSPORTS
}

by Richard J. Weber*

\author{
Lewis Research Center \\ National Aeronautics and Space Administration \\ Cleveland, Ohio
}

\begin{abstract}
Substitution of liquid methane fuel for conventional kerosene promises reductions in direct operating cost of 30 percent or more. The results are affected by whether airplanes are compared on the basis of fixed payload, by the extent to which limits on engine noise nullify the usefulness of methane's superior cooling capacity, and by the delivered cost of the fuel. The best solution to the problem of fuel evaporation during flight is not yet evident.
\end{abstract}

\section{Introduction}

Starting in late 1964, studies have been conducted at the NASA-Lewis Research Center to explore the potential of liquid methane as a fuel for aircraft (refs. 1 to 4). Particular emphasis has been placed on its application to the proposed commercial supersonic transport (SST). The purpose of this paper is to review, for the non-airplane specialist, the results obtained to date.

Since the initiation of these studies, a U.S. Government-sponsored SST design competition has resulted in the selection of two companies to

*Chief, Mission Analysis Branch. 
undertake the construction of a prototype engine and airframe. This prototype design is based on the use of conventional kerosene-type fuel. With the first-generation SST thus well underway and scheduled to enter airline operation by 1977 or so, it is apparent that the prospective use of methane is deferred to second-generation aircraft (assuming, of course, that the current kerosene-fueled airplane development is successful). Realistically, we must recognize in any event that there are presently many uncertainties associated with the use of methane that require resolution in the intervening years.

The incentive for considering methane is indicated in table I. Compared to kerosene, methane has a 13 percent higher heating value and a much greater cooling capacity. Difficulties are to be anticipated, however, in consequence of its low density and low boiling point. Methane might be viewed as a junior version of the ultimate cryogenic fuel, hydrogen, which currently holds little commercial interest because of high cost. In contrast, liquefied natural gas, which is primarily composed of methane, is expected to be quite inexpensive.

\section{Performance Studies}

Engine Design

In terms of engine performance, the use of methane rather than kerosene fuel offers two benefits: (1) the fuel consumption rate, which is inversely proportional to heating value, decreases by approximately 13 percent in engines of otherwise similar design; (2) for equal metal temperature, the turbine-inlet gas temperature can be increased, resulting in both a further reduction in fuel consumption plus higher engine thrust. 
How this second effect may be achieved is indicated in figure 1, which schematically represents a simple turbojet engine. Air enters the engine, is compressed to a high pressure, is raised to a high temperature by combustion of fuel, expands through a turbine which drives the compressor, and finally expands through an exhaust nozzle creating a high-velocity jet. In the engine currently being developed for the SST, the turbine-iniet gas temperature is $2200^{\circ} \mathrm{F}$, which is far above the temperature at which presently available materials retain adequate strength. To keep the metal of the turbine at an acceptable level of about $1700^{\circ} \mathrm{F}$, air is bled from the compressor exit and ducted through cooling passages in the hollow turbine blades. The air leaving the compressor is not a very effective coolant, being itself at a temperature of about $1200^{\circ} \mathrm{F}$. When methane fuel is used, its large heat-sink capability may be applied to cool the compressorbleed air through a heat exchanger as shown. For the same blade metal temperature, this scheme allows raising the turbine-inlet gas temperature co about $2800^{\circ} \mathrm{F}$ (ref. 5).

\section{Airplane Design}

The significance of improvments in engine performance is ultimately demonstrated only in terms of overall airplane performance. Consequently, a high-speed computer was used to generate engine characteristics, to design typical SST airplanes, and to "fly" the engineairplane combinations through standard missions in order to determine range, payload, and cost information.

The selected airplane configuration is pictured in figure 2. Designed by the NASA-Langley Research Center, it yields performance that is similar to the designs that were proposed by the airframe manufacturers during the SST competition. A note of caution must be added here, 
however, now that methane fuel is to be considered: not all configurations are equally adaptable to the use of methane. This is a result of the low density of liquid methane, which requires nearly twice the tank volume of kerosene. The selected configuration was able to contain the bulky methane tanks without much difficulty。Other designs might have required major modification, with attendent penalties in structural weight and aerodynamic drag.

Effect of turbine-inlet temperature. - The preceding section on engine design suggested that high gas temperatures were beneficial. Whether this benefit can be realized in practice is affected to a great extent by the importance of engine noise constraints. High temperatures tend to increase exhaust jet velocity, which in turn increases jet noise. Jet noise at takeoff is a major annoyance to people both at the airport and to the neighboring community. In recognition of this factor, constraints are placed on SST design and operation to insure that takeoff noise is no worse than that of current subsonic airplanes. Strenuous but, as yet, largely unsuccessful efforts are being made to develop a mechanical device to suppress jet noise. In the absence of such a device, noise must be controlled by throttling the engine during takeoff to less than full thrust. This generally requires the installation of a larger, heavier engine, which hurts airplane performance.

This is demonstrated in figure 3 (from ref 6)。 Passenger capacity is shown as a function of design turbine-inlet temperature for a series of airplanes having equal takeoff gross weight and flying 
the same range. The upper set of curves shows data for three different types of engines* when there is no concern over jet noise. All engines benefit from the use of higher temperature. However, all of these cases generate excessive noise. If the engines are redesigned to meet reasonable noise limits, the lower set of curves results. There is now little or no benefit from the availability of high temperature. Thus, the current demand to limit engine noise tends to depreciate the utility of methane's superior cooling capacity.

Comparison with kerosene fuel. - Because the SST is a commercial vehicle, the best means for comparing airplanes is an economic criterion. The one employed here is the direct operating cost (DOC), which is the cost to the airline of operating the aircraft expressed in cents to carry each passenger for one statute mile of flight. DOC includes not only fuel cost but also maintenance, depreciation, and crew expense.

Figure 4 shows DOC as a function of fuel cost. The upper bar is for a reference kerosene-fueled SST that weighs 460, 000 pounds and carries 205 passengers. The two lower bars show the improvement predicted when methane fuel is used, in one case for equal payload and reduced gross weight, and in the other case for equal gross weight and increased payload. Both cases are shown to demonstrate that the method of comparison can affect the results. The lower edge of each bar is for the case where no noise limits are imposed (or where a perfect noise

A, afterburning turbojet; B, non-afterburning turbojet; and C duct.. burning turbofan. 
suppressor is postulated). The upper edge is for the case where noise limits are imposed and are accommodated by engine throttling.

The cost of kerosene fuel is in the order of 1.8 cents/lb. The cost of liquid methane delivered to the airplane is debatable. The cost will depend on the well-head price of natural gas and the liquefaction, shipping, and handling techniques to deliver it to the destination airport. A recent estimate by the Institute of Gas Technology is $1.6 \mathrm{cent} / \mathrm{lb}$, averaged for eight airports around the world but not accounting for economies due to other consumer-use in the vicinity.

For these fuel costs and incorporating the effect of noise limits, the DOC reduction with methane is 14 percent if payload is fixed and 25 percent if gross weight is fixed, assuming constant range in all cases. If noise limits are not required, the reductions are 20 and 30 percent, respectively. (In making these comparisons, the blade metal temperature was fixed at $1700^{\circ} \mathrm{F}$; a lower metal temperature makes methane relatively more attractive.)

For the most part, these reductions are highly significant. Even 14 percent is well worthwhile, but it is only realistic to recognize that theoretical benefits such as predicted here usually tend to diminish when put into practice.

Evaporation losses. - One foreseeable difficulty that could diminish the theoretical benefits if not solved is evaporation or boiloff during flight. Liquid methane at its normal boiling point of $-259^{\circ} \mathrm{F}$ is far below the sea level ambient temperature. The situation is still worse when cruising at Mach 3, where the skin of the airplane is heated by 
aerodynamic friction to $500^{\circ}$ to $600^{\circ} \mathrm{F}$. A moderate amount of insulation is adequate to limit evaporation due to thermal leaks to an acceptable level, particularly if the vapor evolved during cruise can be pumped into the engines and burned. Probably the major problem here lies in finding an insulation material that can reliably withstand temperature cycling between $-259^{\circ}$ and $600^{\circ} \mathrm{F}$. Determining practical installation and inspection techniques may also prove difficult.

Oddly enough, the most worrisome evaporation problem is not that caused by heating. Rather, it is the reduction in ambient pressure dur ing climb that causes most concern (although it is not intended to give the impression that the difficulties of developing a reliable, durable insulation system are not considerable). Liquid methane, as normally produced, is a boiling liquid with a vapor pressure of one atmosphere at a temperature of $-259^{\circ} \mathrm{F}$. Conventional airplane fuel tanks are not capable of withstanding very large pressure differences so that, as the airplane climbs, the internal tank pressure is allowed to drop at about the same rate as the external ambient pressure. To maintain pressure equilibrium, enough methane must "flash" or boil away to cool the remaining liquid to a lower temperature and lower vapor pressure.

The magnitude of this effect is shown in figure 5. The SST will cruise at altitudes of about 70,000 feet where the ambient pressure is less than one psia. If the tank pressure were allowed to fall to this level, an exorbitant amount of methane would be lost. Fortunately, the usual airplane tank design can stand some internal pressure, perhaps 4 to 6 psig. This limits the boiloff loss to a more manageable, but still high, 7 percent or so. 
The importance of minimizing boiloff is indicated in figure 6 . Boiloff losses can appreciably reduce the DOC advantage of methane over kerosene. The fixed-payload, variable-gross-weight case is seen to be less sensitive than the fixed-gross-weight case (but recall that the maximum potential gain is also less for the fixed-payload case).

Many techniques can be envisioned for treating the problem of pressure-induced boiloff, as listed in table II. (Some of these have been evaluated in refs. 7 to 9). The first group of techniques applies to methane that is initially in the saturated, boiling condition at one atmosphere. Strengthening the tanks to preserve this internal pressure throughout the flight (thus preventing boiloff) is conceptually the simplest approach. Preliminary studies of tanks that can withstand the resulting 14-psi pressure differential give hope that the weight penalties will not be excessive. The other techniques in this first group permit the methane vapor to evolve and then seek to utilize it in some fashion. Significant weight penalties are suffered in all cases.

The second approach in table II is to subcool the fuel before placing it in the airplane. If the vapor pressure is sufficiently low, there will be no flashing of vapor as the airplane climbs to high altitude. The problem is now one of preventing the tanks from crushing inward while at low altitude due to the imbalance of internal and external pressures. Various types of pressurizing gases can be considered for this purpose, each having difficulties.

In general, it is apparent that there are numerous possible approaches to preventing excessive boiloff losses with methane fuel. The best solu- 
tion is not yet evident, but there is reasonable hope that an acceptable one can be found.

\section{Concluding Remarks}

Analytical studies performed at the Lewis Research Center and confirmed by others have pointed out that methane fuel may offer substantial benefits for future commercial supersonic transports. The original performance estimates have been recently modified, but not negated, by closer attention to the noise problem. Several prospective solutions have been advanced for the boiloff problem, but further study is required. More detailed studies of the general methane concept, together with preliminary experimental work, are planned.

It is expected that, with sufficient effort, all the technical problems associated with methane fuel can be overcome. However, the SST is a commercial venture. Therefore, the economic, political, and safety aspects of introducing a new and unusual fuel into world-wide use must also receive close scrutiny in the coming years.

\section{$\underline{\text { References }}$}

1. R. J. Weber, J.F. Dugan, Jr., and R. W. Luidens, "MethaneFueled Propulsion Systems, " AIAA Paper 66-685 (1966); also Astronautics and Aeronautics $\underline{4}$ (10), 48 (1966).

2. J. B. Whitlow, Jr., J. D. Eisenberg, and M. D. Shovlin, "Potential of Liquid-Methane Fuel for Mach 3 Commercial Supersonic Transports," NASA TN D-3471 (1966); also Cryogenic Technology 3, 243 (1967). 
3. R. J. Weber, "Liquefied Natural Gas as a Fuel for Supersonic Aircraft," Distribution Conference of the American Gas Association, St. Louis, Missouri, May 1967 (also Oil and Gas Journal 65, (1967).

4. B. A. Miller, "Analysis of Several Methane-Fueled Engine Cycles for Mach 3.0 Flight, Proposed NASA Technical Note.

5. F. Stepka, "Considerations of Turbine Cooling Systems for Mach 3 Flight," NASA TN D-4491 (1968)。

6. R. W. Koenig and G. A. Kraft, " ${ }^{\circ E f f e c t}$ of Takeoff Jet Noise on Benefits of High-Turbine-Inlet-Temperature Engines to a MethaneFueled SST ${ }^{"}$ Proposed NASA Technical Note。

7. J. D. Eisenberg and R. E. Chambellan, "Tankage Systems for a Methane-Fueled Supersonic Transport, "AIAA Paper 68-196 (1968).

8. R. E. Chambellan, J. F. Lubomski, and W. A. Bevevino, 'Structural Feasibility Study of Pressurized Tanks for Liquid-Methane Fueled Supersonic Aircraft, ${ }^{\ominus}$ NASA TN D-4295 (1967).

9. R. J. Weber, "The Boiloff Problem with Methane Fuel in Super sonic Aircraft, " NASA TM X-1604 (1968). 
TABLE I. - FUEL PROPERTIES

\begin{tabular}{|c|c|c|c|c|c|}
\hline Fuel & $\begin{array}{c}\text { Heat of } \\
\text { combustion, } \\
\text { Btiu/10 }\end{array}$ & $\begin{array}{c}\text { Heat-sink } \\
\text { limit } \\
\text { temperature, } \\
{ }^{0} F\end{array}$ & $\begin{array}{c}\text { Heat sink, } \\
\text { Btu/lb }\end{array}$ & $\begin{array}{c}\text { Density, } \\
\mathrm{lb} / \mathrm{ft}^{3}\end{array}$ & $\begin{array}{c}\text { Boiling } \\
\text { point, } \\
{ }^{O_{F}}\end{array}$ \\
\hline Kerosene-type & 18,700 & $375-700$ & $165-365$ & 50 & 300 \\
\hline Methane & 21,200 & 1000 & 1100 & 26.5 & -259 \\
\hline Hydrogen & 51,600 & 1000 & 4900 & 4.3 & -423 \\
\hline
\end{tabular}


TABLE II. - METHODS OF BOILOFF CONTROL

Saturated Methane

High-pressure tank

Liquefy vapor

Adsorb vapor

Burn vapor in engine

Vent vapor overboard

Subcooled Methane

Non-condensable pressurants

Expended; recovered

Condensable pressurants

Dissolved in fuel; not dissolved

Zero-ullage 


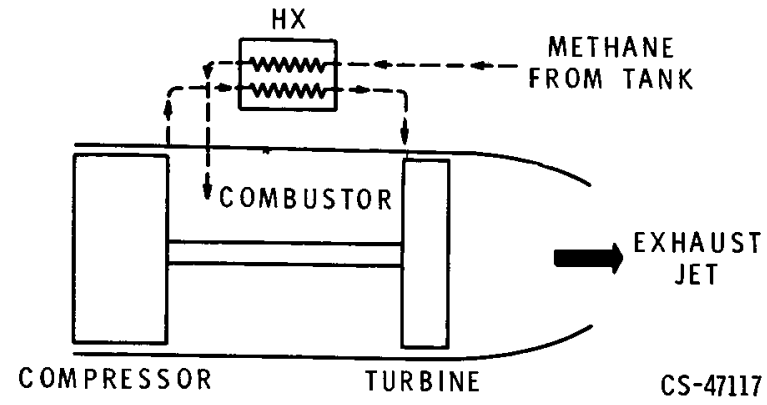

Figure 1. Schematic of turbojet engine with cooled turbine.

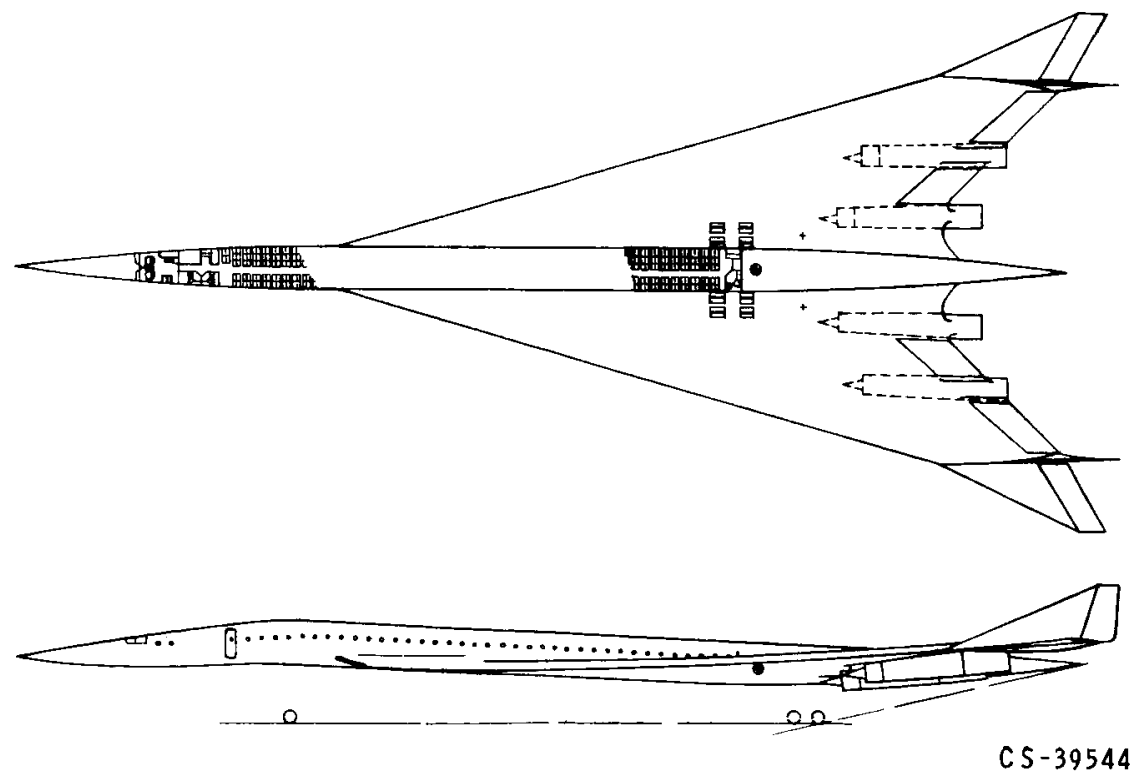

Figure 2. Typical SST configuration. 


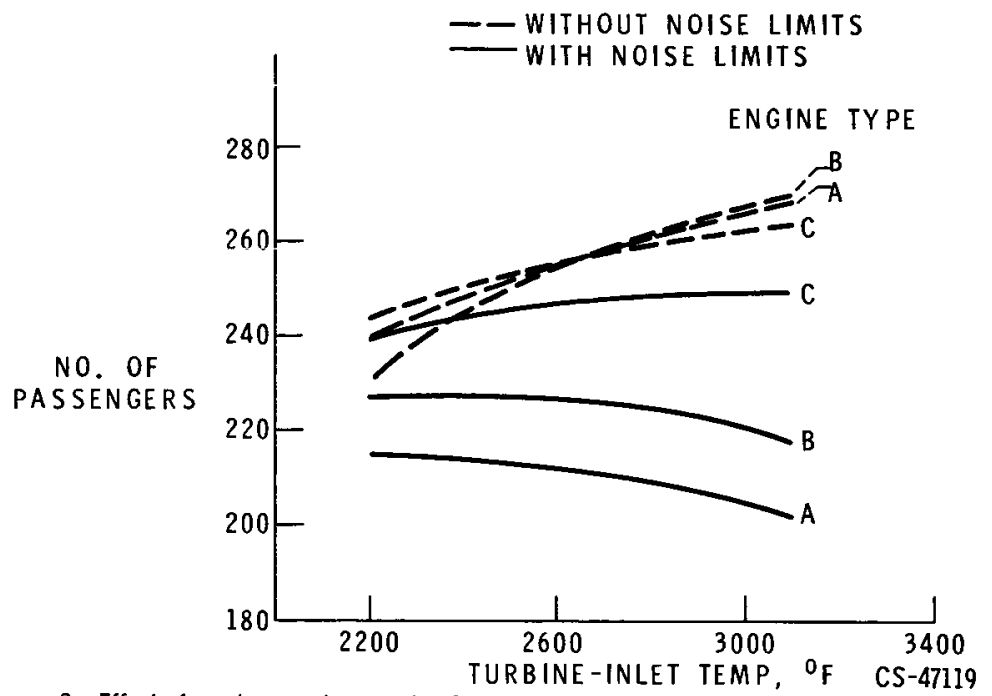

Figure 3. Effect of gas temperature and noise constraints. Cruise Mach number, 3; gross weight, $460,000 \mathrm{lb}$.; range, 4000 statute miles.

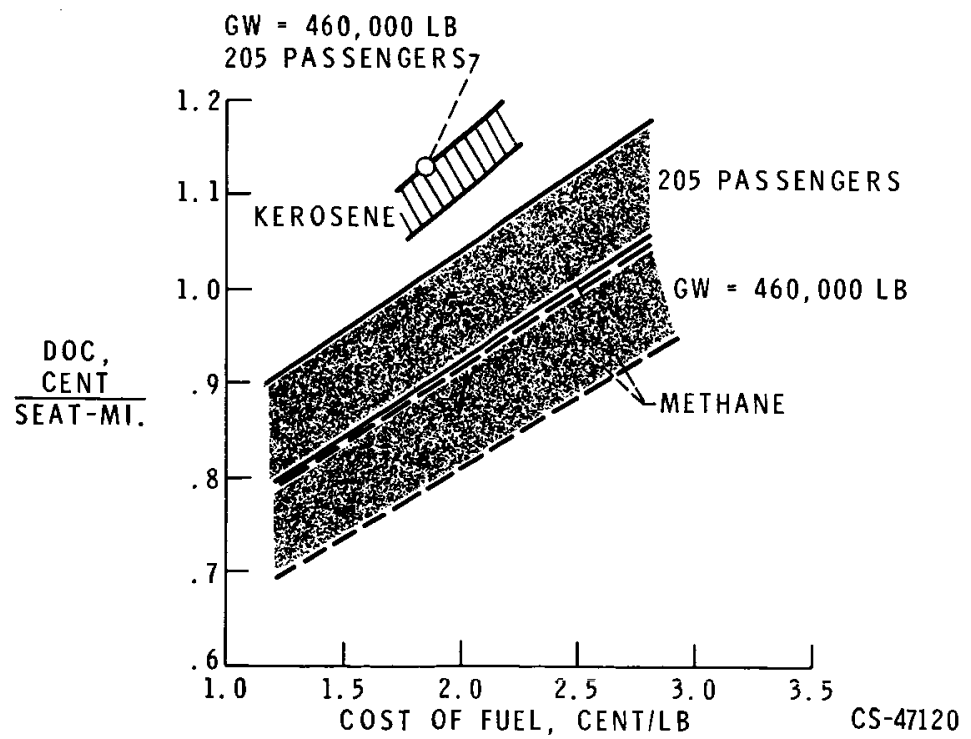

Figure 4. - Comparison of kerosene and methane fuel. Cruise Mach number, 3; range, 4000 statute miles. 


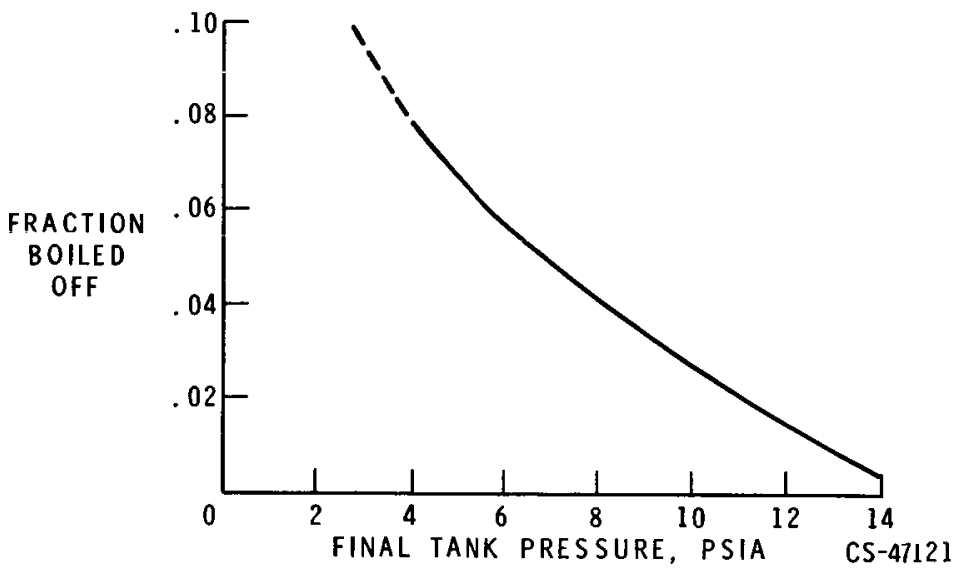

Figure 5. Methane boiloff due to tank venting. Initial tank conditions, $-259^{\circ} \mathrm{F}$ and $14.7 \mathrm{psia.}$

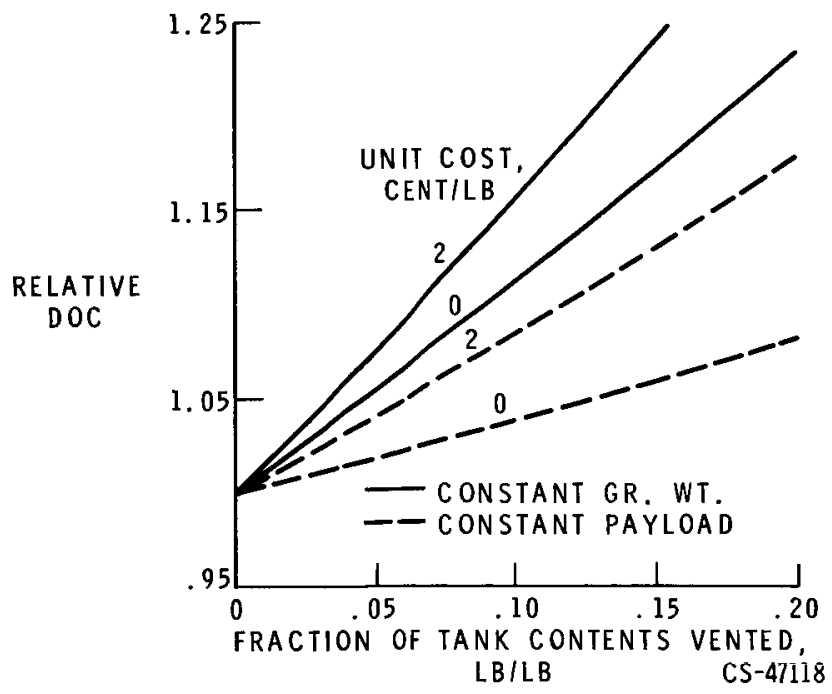

Figure 6. Penalty in direct operating cost due to venting. Methane cost, 2 cents/lb; turbine-inlet temperature, $2200^{\circ} \mathrm{F}$. 